Article

\title{
The Impact of High-Speed Rail Opening on City Economics along the Silk Road Economic Belt
}

\author{
Feng Li ${ }^{1}$, Yang $\mathrm{Su}^{2, *}$, Jiaping Xie ${ }^{1,3}$, Weijun $\mathrm{Zhu}^{3}$ and Yahua Wang ${ }^{4,5}$ \\ 1 School of Business Administration, Xinjiang University of Finance \&Economics, Urumqi 830052, China; \\ lifeng@xjufe.edu.cn (F.L.); jiaping@mail.shufe.edu.cn (J.X.) \\ 2 College of Economics and Trade, Xinjiang Agricultural University, Urumqi 830052, China \\ 3 School of international business administration, Shanghai University of Finance and Economics, \\ Shanghai 200433, China; zhu.weijun@163.sufe.edu.cn \\ 4 School of Public Policy and Management, Tsinghua University, Beijing 100084, China; \\ wangyahua@tsinghua.edu.cn \\ 5 China Institute for Rural Studies, Tsinghua University, Beijing 100084, China \\ * Correspondence: suyang@xjau.edu.cn
}

Received: 9 March 2020; Accepted: 13 April 2020; Published: 15 April 2020

check for updates

\begin{abstract}
Achieving transport connectivity is a priority in China's "Belt and Road Initiative". In order to further understand the impact of railway infrastructure on city-level economic expansion, we set cities with high-speed rail as the treatment group and those without high-speed rail as the control group, and a difference-in-differences (DID) technique was used to estimate the growth impact and heterogeneity of high-speed rail opening on the economic growth of cities along the New Silk Road Economic Belt. The main results are as follows: First, economic growth in cities with operational high-speed rail lines was significantly higher than those without high-speed rail. Second, the impact of high-speed rail on economic growth exhibited distinct heterogeneity. Large cities tend to have a stronger siphoning effect, resulting in more pronounced impact of high-speed rail opening on urban economic growth. Third, cities with higher marketization levels and higher government efficiency were shown to have stronger economic growth effect.
\end{abstract}

Keywords: high-speed rail opening; the Silk Road Economic Belt; economic growth; heterogeneity

\section{Introduction}

The Silk Road has provided important contributions to the global economic and cultural exchanges with far-reaching historical significance. However, this once-prosperous economic corridor has been overtaken and left behind by other regions. As strategies for China's economic development become more regionalized, plans to revitalize the economy of the Silk Road have been proposed. In 2013, China's President Xi Jinping put forward the concept of the "New Silk Road Economic Belt". In 2015, the National Development and Reform Commission, the Ministry of Foreign Affairs, and the Ministry of Commerce in China jointly issued the "Visions and Actions for Promoting the Joint Construction of the Silk Road Economic Belt and the 21st Century Maritime Silk Road" (hereinafter referred to as the "Belt and Road Initiative"), which aims to develop the Silk Road as a powerful venue to promote economic development along its route and create a "community of common destiny" with shared political trust, economic integration, and cultural tolerance.

In order to support the progress of the "New Silk Road Economic Belt", an interconnected transportation network has to be developed. In recent years, the construction of transportation infrastructure has been in full swing in various regions of China, which has entered the high-speed rail era. According to statistics, China's high-speed rail has had an operating mileage of over 35,000 kilometers by the end of 2019, ranking steadily at No.1 (CCTV, 30 December 2019). 
Realizing the "Eight Vertical and Eight Horizontal" blueprint in high-speed rail construction would further expand the range of the current high-speed rail network, which will bring the rapid flow of talents, capital, technology, information, and other elements, and becomes the "fast way" to promote the development of the local economy. This is critical in order to maintain stable growth of regional economies while achieving high-quality economic development. Under this backdrop, we examine the impact of high-speed rail system on the economic growth of cities, focusing on the New Silk Road Economic Belt as the study site. Overall, the high-speed rail network is more extensive in eastern China, while the Silk Road Economic Belt is located in the west. This leads to a number of important questions that need to be examined: Does the high speed-rail network have a promotional effect on regional economic development? What is the impact mechanism of the various factors? Does any promotional effect demonstrate heterogeneity under different urban scales, marketization levels, and government efficiency? In order to answer these questions, a DID differential analysis was conducted on regions with and without high-speed rail. We also explore the heterogeneity of the high-speed rail effect and characterize some of its underlying aspects. The results of this study provide a basis for each region to further expand regional development space, promote regional economic growth and formulate relevant policies according to local conditions with the help of high-speed rail construction

\section{Literature Review}

Transportation infrastructure is essential for driving regional economic growth [1,2]. As early as the 20th century, many foreign economists have proposed theories explaining the relationship between transportation infrastructure construction and economic development. For example, Rodan's (1943) "big push" theory suggests that the development of infrastructure such as transportation is a crucial prerequisite for economic take-off [3]. Nurkse (1966, Editor Zhai J) argues that the government should take the primary responsibility in infrastructure investment to promote economic growth [4]. Rostow (1960s) "stage of economic growth" theory suggests that developing countries should give priority to the development of transportation infrastructure [5]. In the late 20th century, as an important technological innovation, the emergence of high-speed rail has considerably reduced the commuting time between regions, indicating significant improvements in the level of transportation infrastructure. The rapid development of high-speed rail has also stimulated research interests among local and international scholars regarding the relationship between high-speed rail and economic growth.

Research on the economic effects of high-speed rails is mainly implemented at the macro-level or at the micro-level. Previous studies at the macro-level analysis have mainly focused on the impact of high-speed rail opening on economic growth, economic agglomeration, and economic gaps. Two contrasting views have been proposed, with one suggesting that high-speed rail can drive regional economic growth. Kim (2000) studied the development of high-speed rail in Japan and Europe and found high-speed rail enhance interregional accessibility and promote regional economic growth by influencing the location and career choices of residents [6]. Albalate (2016) concluded that high-speed rail save on costs, promote employment, and subsequently stimulate regional economic growth [7]. Wang and $\mathrm{Li}$ (2014) studied the economic development of cities along the Shanghai-Hangzhou high-speed rail line and found that the inauguration of high-speed rail has a significant role in promoting the economic growth of cities along the line [8]. Another view states that this driving effect is ambiguous, which can promote economic aggregate significantly in the short term but has less effect on economic growth [9]. This is mainly due to the fact that the impact of high-speed rail on regional economic growth hinges on factors such as network layout, construction cost, and environmental cost [10-13].

On the subject of economic agglomeration, the impact of high-speed rail on cities along the railway is indefinite. Some scholars believe that the economic agglomeration levels of cities along the line have shown significant improvements with high-speed rail, promoting the economic agglomeration level of the regional economy [14-17]. However, the imbalance embedded in the high-speed rail network construction has a different impact on cities with heterogeneous geographical location and economic 
development level. In essence, the status of central cities could be enhanced, while peripheral cities might run the risk of being marginalized. Thus, the economic impact of high-speed rail on cities along the route can be either an agglomeration effect or a diffusion effect, which can be revealed by analyzing the impact mechanism of high-speed rail on urban agglomeration.

With respect to economic gaps, most studies have shown that high-speed rail has improved the accessibility of cities, making the production factor resources of the surrounding regions congregate around node cities. As well, while the introduction and expansion of high-speed rail encourage economic growth, cities not covered by the system may be adversely affected [10,18-20] However, some scholars disagree with this view. For example, Li et al. (2016) suggest that at the national level, high-speed rail promotes economic agglomeration in China's western region and is conducive to equalizing economic disparities [21]. Similarly, while studying China's Fujian Province, Li and Huang (2018) found that the spillover effect of county-level economic growth decreases after opening the high-speed rail, which supports a more balanced development of the regional economy [22].

Some studies suggest that the opening of the high-speed rail provides big cities with better "relative accessibility", while small and medium-sized cities also get "absolute accessibility" improvement [23]. It has been suggested that high-speed rail has led to the spatial polarization development of the tertiary industry in large cities and that it has stimulated the division of work and cooperation between large cities and small and medium-sized cities and the balanced development of the secondary industry. High-speed rail has promoted the "urbanization effect" between adjacent large cities, but it is still considered to be at the initial stage of urbanization. High-speed rail also enables small and medium-sized cities around megacities to gain the beneficial effect of the diffusion ring [24,25]. Therefore, the impact of high-speed rail on the economic development of different scale cities has not been consistent.

Aside from analyzing at the macro-level, studies regarding high-speed rail have been implemented at the micro-level. Micro-level analysis mainly focuses on the impact of the high-speed rail system on corporate innovation, investment, and productivity. By shortening business travel time, high-speed rail facilitates communication and cooperation among enterprises, accelerates the flow of factors such as capital and technology, and reduces information asymmetry [26], all of which are conducive to improving the competitiveness of enterprises. Du and Peng (2017) found that the opening of high-speed rail enhances city attractiveness, attracts more highly educated talents, promotes interregional flow of innovation elements including technology and knowledge, and increases innovation investment of enterprises [27]. Similarly, Tan et al. (2019) analyzed the relationship between high-speed rail and corporate innovation. They found that compared to cities without high-speed rail, the number of patent applications is significantly higher for listed companies in cities with high-speed rail [28]. Long et al. (2017) studied the impact of high-speed rail on regional investment in terms of venture capital. They found that high-speed rail facilitates face-to-face communication between investors and companies, which can help reduce information asymmetry and attract more venture capital [29]. Wen et al. (2019) also found that the opening of high-speed rail increases investment efficiency and subsequently improves industrial performance [30]. Huang and Sun (2019) found that high-speed rail improves total factor productivity and affects non-state-owned businesses more distinctly than state-owned enterprises [31].

Research in the field of high-speed rail and economic growth has been growing, yielding important results. However, there are varying opinions regarding the relationship between high-speed rail and the national economy, and a convincing theoretical explanation is missing dissecting the internal mechanism of that relationship. The "Belt and Road Initiative" is an important national strategy for China in the context of its opening-up and expansion to the outside world. The economies on the New Silk Road Economic Belt is relatively backward, which makes improving the transportation infrastructure and the inter-regional interconnection particularly crucial for these regions' future development. 


\section{Mechanism Analysis of High-Speed Rail's Impact on Economic Growth}

\subsection{High-Speed Rail Opening and Economic Growth}

According to The New Economic Geography, the progressive improvements in transportation infrastructure, while driving regional economic growth, would lead to an interregional transfer of various economic factors. This would result in significant changes to the spatial distribution pattern of regional economies, referred to as the "economic distribution effect" [32]. As a crucial transportation infrastructure, high-speed rail system can significantly affect the regional economic structure. These economic consequences can be classified into three aspects: the same-city effect, the corridor effect, and the siphoning effect [18].

The same-city effect refers to the economic linkages between neighboring cities through the high-speed rail network that promotes regional urban integration. As indicated by numerous studies, high-speed rail, characterized by speediness, convenience, and punctuality, can significantly reduce commuting time, improve accessibility between adjacent cities, and generate a space-time compression effect $[10,30]$. These benefits help encourage urban economic exchanges and cooperation. With the same-city effect, the flow of factors such as people, material, capital, and information can go much freely with lower transportation and transaction costs and at a higher efficiency. This results in strengthened economic connections between adjacent cities and promotes economic development.

The corridor effect means that with the opening of high-speed rail, axial connections between cities become more pronounced due to the increased accessibility. Cities along the high-speed rail line also have relatively high external and inter-pair links, thus forming an economic "corridor" [33]. With the railway network, transportation costs of goods and elements between cities at any node along the line would decrease. Also, the railway's carrying capacity would be significantly improved and thus achieving smoother and more frequent economic exchanges between cities. The economic ties formed would help optimize resource allocation, generate an industrial belt along the high-speed rail, and foster economic expansion of cities along its route. Research has shown corridor effect from high-speed rail results in higher income for cities along the rail line compared to those not serviced by a high-speed rail system [34,35].

The siphoning effect suggests that instituting a high-speed rail system strengthens a city's geographic advantage and promotes the agglomeration of funds, talents, and information to cities along the rail line. Rational manufacturers are predisposed to build up their production resources in high traffic locations to reduce costs, and cities along high-speed rail provide such an advantage. Also, resource allocation in the surrounding areas gradually changes. Various resource elements become concentrated in cities with high-speed rail, enhancing their concentration capacity and resulting in both agglomeration effect and polarization phenomenon. These advantages and effects further stimulate economic activities in cities along the high-speed rail route [13].

Figure 1 shows the contrast of economic growth of cities with high-speed rail (i.e., cities that have opened a high-speed rail in 2014) and those without high-speed rail. Before 2014, the economic growth trajectories of the treatment group (cities with a high-speed rail) and the control group (cities without a high-speed rail) have been largely identical, whether in terms of total GDP or per capita GDP. However, after the high-speed rail was opened (i.e., post-2014), the economic growth of the control group slowed down, while the treatment group continued to expand. This could imply that the opening of high-speed rail generates a positive impact on urban economic growth. Based on the above theoretical and statistical analyses, we propose the following hypothesis: 

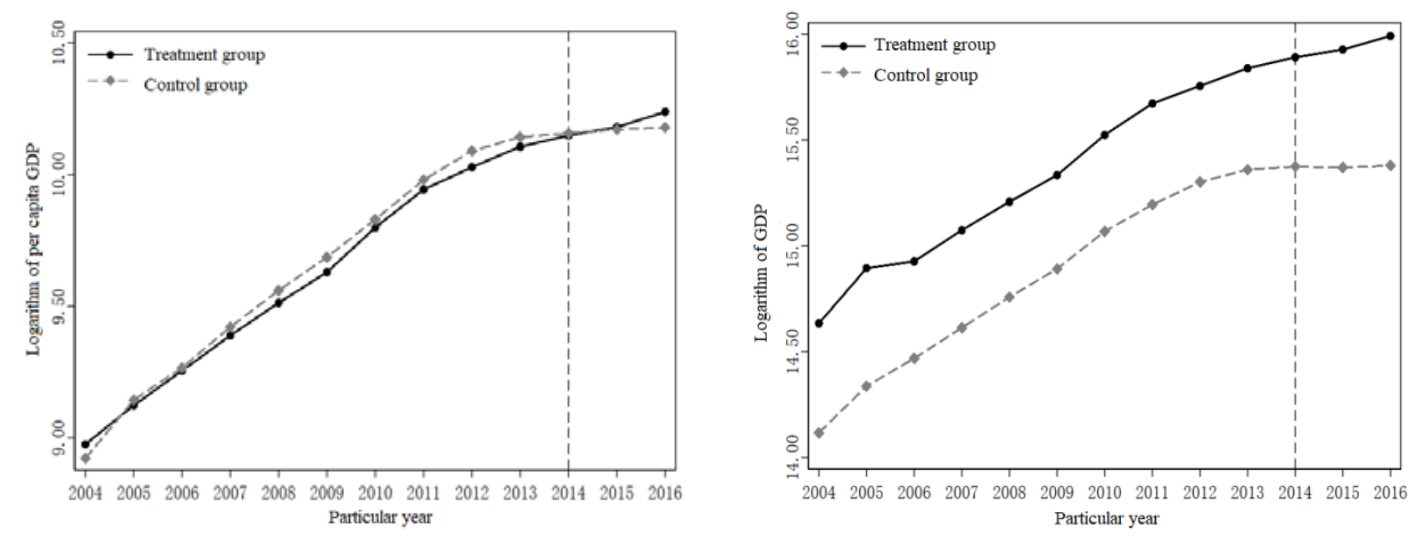

Figure 1. The trend of economic growth. Data source: China Statistical Yearbook, organized by the authors.

Hypothesis 1: The opening of high-speed rail is conducive to urban economic growth.

\subsection{Impact Heterogeneity of High-Speed Rail Opening Regarding Urban Scale}

High-speed rail can affect the spatial distribution of regional economies through centrality, accessibility, and connectivity. Due to differences in the economic status and scale of node cities in the network, the impact of high-speed rail on the economic growth of each city varies. Usually, the size of a city determines its agglomeration capacity. Compared with small and medium-sized cities, large cities tend to have stronger capability in resource attraction and allocation, more opportunities for industrial development, and stronger effect on driving regional economic growth.

While various resource elements accumulate around cities along high-speed rail, the siphoning effect of large cities is usually considerably stronger. Due to their location advantages, large cities may be able to attract additional resource elements from proximate small and medium-sized cities [36], thus reducing the agglomeration capacity of these cities. This suggests that the size of the cities can influence the impact of opening high-speed rail on the local economy. The benefits for larger cities tend to be more prominent compared to small and medium-sized cities due to the resource outflow $[18,37]$. Based on the above analysis, we propose the following hypothesis:

Hypothesis 2: The economic effect of high-speed rail opening is influenced by urban scale. The effect on economic growth is stronger for big cities compared to small and medium-sized towns.

\subsection{Impact Heterogeneity of High-Speed Rail Opening Regarding Marketization and Government Efficiency}

New Structural Economics argues that an efficient market and a proactive government are necessary to guarantee economic development and transformation [38]. While opening high-speed rail can strengthen a city's location advantage and its ability to attract resources, the market and the government are the ones that make the resources work. On the one hand, competition is generally sufficient in regions with well-developed markets, and the profit-seeking nature of enterprises enables industries to make choices and allocate resources based on their comparative advantages. This allows the flow of limited resources into high-efficiency fields [38,39], resulting in improved competitiveness. On the other hand, in areas where government efficiency is high, the government is mainly committed to creating a fair and efficient market environment. Interventions by administrative forces in the market are generally weak; thus, resource elements can be allocated more efficiently. This helps avoid the problem of resource mismatch [40] and is conducive to achieving sustained economic growth. Based on the above analysis, we propose the following hypotheses: 
Hypothesis 3: The degree of marketization of a city influences the impact of high-speed rail opening on economic growth. Cities with a higher degree of marketization have stronger economic growth effects.

Hypothesis 4: Efficiency of the urban government affects the impact of high-speed rail opening on economic growth. Cities with a more efficient government have stronger economic growth effects.

\section{Model and Data}

\subsection{Model Setting}

In China, high-speed rail construction is within the purview of the national-level strategic plan. Local governments often do not know of the plans regarding the construction of high-speed rail before the formal announcement by the central government [41]. In addition, building a high-speed rail station is not determined by a city's economic scale, but whether it is geographically connected to the central city. In general, high-speed rail construction can be characterized as having a certain degree of randomness, which can be represented by a quasi-natural experiment. Based on the recommendations from previous research, in this study, we set cities with high-speed rail as the treatment group and those without high-speed rail as the control group. We introduced a dummy variable, hsr, which was set to zero for the control group. For the treatment group, the value was set to zero before the opening of the high-speed rail and set to one after the opening. A difference-in-differences (DID) technique was then used to estimate the net effect of high-speed rail opening on urban economic growth. The benchmark model is set as follows:

$$
\ln Y_{\text {it }}=\alpha+\beta \times h s r_{i t}+\theta \times X_{i t}+\lambda_{i}+\tau_{t}+\varepsilon_{i t}
$$

where the subscripts $i$ and $t$ indicate the city and year, respectively; $Y$ is the explained variable; $X$ is a set of control variables used to control the economic characteristics of each city; $h s r$ is the high-speed rail opening variable; $\alpha$ is the constant term; $\lambda$ is the urban fixed effect; $\tau$ is the year fixed effect; and, $\varepsilon$ is the random error term. The parameter $\beta$ is the primary focus of this study. If $\beta>0$, the opening of high-speed rail is conducive to urban economic growth; if $\beta<0$, the opposite is true; and if $\beta=0$, the high-speed rail opening makes no significant contribution to urban economic growth.

\subsection{Sample and Data Selection}

As stated in the "Belt and Road Initiative", the New Silk Road Economic Belt comprises six northwestern provinces (Xinjiang, Shanxi, Gansu, Ningxia, Qinghai, and Inner Mongolia), three northeastern provinces (Heilongjiang, Jilin, and Liaoning), and three southwestern provinces (Guangxi, Yunnan, and Tibet). In this study, 89 cities from these 12 provinces were considered as part of the sample population, wherein 43 cities formed the treatment group (with high-speed rail), and the remaining 46 cities formed the control group.

Explained variable (Y). Generally, urban economic growth is measured through the GDP. However, for this study, given pronounced scale differences existing among cities, we modified the index to per capita GDP.

High-speed rail opening variable (hsr). The values were set as follows: when city $i$ opened high-speed rail in year $t$, the value of $t$ (and later years) is set to 1 , while the value of year before $t$ is 0 . Thus, the $h s r$ variable of the control group is always 0 ; while. the $h s r$ variable of the treatment group is 0 before the opening of the high-speed rail, and 1 afterward.

Control variable $(X)$. Aside from the opening of high-speed rail, other factors have significant impact on urban economic growth. In order to exclude the influence of other factors, we added several control variables to the benchmark model. In the classical Cobb-Douglas function, labor and capital input are used to model economic growth. For this study, these two variables were added as control variables. Labor input was denoted by population density (lnpop) and was measured by population per square kilometer. The higher the population density, the higher the labor input. Capital input was 
expressed by capital stock $(\ln k)$, estimated using the perpetual inventory method. The annual physical capital stock was calculated according to the constant price index in 2004, and the depreciation rate was set to $9.6 \%$. For more details on the calculation methods, see Zhang et al [42]. Additional factors that were used as control variables in this study include the following: the level of innovation (inno), measured by the Urban Innovation Index in China Urban and Industrial Innovation Report 2017; foreign investment (lnfdi), measured by the amount of direct foreign investment per capita; financial development level (lnfina), measured by the proportion of loan balance of financial institutions in urban GDP; industrial structure (lns), measured by the proportion of the secondary industry; and wage level (lnwage), measured by the average wage of employed workers (see Table 1).

Table 1. Description of variable settings.

\begin{tabular}{|c|c|c|c|}
\hline Variable Type & Variable & Definition & $\begin{array}{l}\text { Expected Impact } \\
\text { Direction }\end{array}$ \\
\hline \multirow{2}{*}{ Dependent Variables } & $\ln g d p$ & GDP & none \\
\hline & $\ln p g d p$ & Per capita GDP & none \\
\hline \multirow[t]{3}{*}{ Policy Variable } & hsr & High-speed rail opening variable & + \\
\hline & $\ln$ pop & $\begin{array}{l}\text { Labor input, measured by } \\
\text { population density }\end{array}$ & + \\
\hline & $\ln k$ & Capital input, measured by capital stock & + \\
\hline \multirow[t]{5}{*}{ Control Variables } & $\ln s$ & $\begin{array}{l}\text { Industrial structure, measured by the } \\
\text { proportion of secondary industry }\end{array}$ & + \\
\hline & lnwage & $\begin{array}{l}\text { Wage level, measured by the average wage } \\
\text { of employed workers }\end{array}$ & + \\
\hline & inno & $\begin{array}{l}\text { Innovation level, measured by the Urban } \\
\text { Innovation Index }\end{array}$ & + \\
\hline & $\ln f d i$ & $\begin{array}{l}\text { Foreign investment, measured by the } \\
\text { amount of direct foreign investment } \\
\text { per capita }\end{array}$ & $+/-$ \\
\hline & $\ln$ fina & $\begin{array}{l}\text { Financial development level, measured by } \\
\text { the proportion of loan balance of financial } \\
\text { institutions in urban GDP }\end{array}$ & $+/-$ \\
\hline
\end{tabular}

In total, we collected the panel data of 89 cities on the New Silk Road Economic Belt from 2004 to 2016. Economic data were obtained from the China City Statistical Yearbook, the China Statistical Yearbook, and the China Urban and Industry Innovation Report 2017. All economic data were calculated as actual indicators based on the price index for 2004. The situation of high-speed rail opening in each city was determined using information from China's high-speed rail website (www.gaotie.cn). Descriptive statistics for each variable are shown in Table 2.

Table 2. Descriptive statistics of variables.

\begin{tabular}{ccccccc}
\hline Variable Type & Variable & Sample Size & Mean & Standard Deviation & Minimum & Maximum \\
\hline \multirow{2}{*}{ Dependent variables } & $\ln g d p$ & 1157 & 15.3141 & 0.9427 & 12.7899 & 18.0145 \\
Policy variables & $\ln p g d p$ & 1157 & 9.8716 & 0.7977 & 7.7577 & 12.2121 \\
& $\operatorname{ls} r$ & 1157 & 0.1599 & 0.3667 & 0 & 1 \\
& $\ln p o p$ & 1157 & -4.3224 & 0.9079 & -7.6629 & -2.5055 \\
& $\ln k$ & 1157 & 10.2601 & 0.5270 & 8.7335 & 11.8284 \\
Control variables & $\ln s$ & 1157 & 2.4793 & 9.1760 & 0.0000 & 141.4800 \\
& $\ln w a g e$ & 1157 & -0.8012 & 0.3037 & -2.4079 & -0.0946 \\
& inno & 1157 & 7.0286 & 1.1742 & 3.5881 & 10.2122 \\
& $\ln f d i$ & 1157 & -0.6548 & 1.4877 & -7.0007 & 2.4243 \\
& $\ln f i n a$ & 1157 & -0.3375 & 0.5296 & -2.5860 & 1.5489 \\
\hline
\end{tabular}

\section{Empirical Results and Analyses}

\subsection{Benchmark Model}

The results of the regression analysis of the benchmark model using the DID method are presented in Table 2.when no additional control variables were included in the regression model (column 1), the coefficient of the core explanatory variable $(h s r)$ is positive $(p<0.10)$. When control variables were added to the model (column 2), the coefficient of $h s r$ remains positive with a higher significance level 
$(p<0.01)$. This suggests that among the cities on the Silk Road Economic Belt, economic aggregation in cities with high-speed rail is significantly greater than those without. In terms of per capita GDP, when control variables were not included (column 3), the coefficient of $h s r$ is positive but not significant. When control variables were added to the model (column 4), the coefficient of $h s r$ is also positive and passes the $10 \%$ significance level test. This suggests that compared with cities without a high-speed rail, the per capita GDP is significantly higher for cities with operational high-speed rail. These results confirm Hypothesis 1, indicating that in the New Silk Road Economic Belt region, the opening of high-speed rail is conducive to urban economic growth.

\subsection{Parallel Trend Test}

The parallel trend test is an important prerequisite when adopting the DID model. Parallel trend means that the growth rate of the dependent variable should be consistent for the treatment group and the control group before receiving treatment [43]. The sample parallel trend test can be conducted by adding the interaction term of the dummy variable with the treatment variable of each year before treatment. If the dummy variable is insignificant, the assumption of a parallel trend can then be established. As earlier discussed, the economic growth rates of the control and treatment groups are similar (see Figure 1), which means that the parallel trend hypothesis is satisfied. However, since Figure 1 only comprises economic growth data from 2004-2016, other years have not been taken into account, which could result in possible bias. Moreover, the trend graph lacks strict statistical tests, which would determine if the difference between the two groups is significant or not. In this regard, we follow the recommendations from existing literature, and conducted a parallel trend test by setting the model as follows:

$$
\ln Y_{i t}=\alpha+\sum_{k=-12}^{13} \rho_{k} A_{i t k}+\theta \times X_{i t}+\lambda_{i}+\tau_{t}+\varepsilon_{i t}
$$

Variable $A$ comprises 26 dummy variables; $k<0$ means $k$ years before the high-speed rail was opened; $k>0$ means $k$ years after the high-speed rail opening; and, $k=0$ means the exact year of the opening. Variable $A$ is set using the following rules: If the sample year $k>0$ or $k<0$, the value of $A$ is 1 , the value of $k=0$, and the value of $A$ is 0 . The earliest year of opening high-speed rail was in 2003 (Qin-Shen Passenger Dedicated Line), and the newest lines were inaugurated in 2016 (Shanghai-Kunming high-speed rail, Kunyu inter-city railway, Nanning-Kunming high-speed rail). Therefore, we got a total of 26 dummy variables.

We then sorted the dummy variables chronologically and found very few samples in the treatment group at both ends. Thus, we excluded the dummy variables at the extreme ends with insufficient samples and limited the scope to the period five years pre-opening and eight years post-opening of the high-speed rail. Figure 2 shows the estimation results using Equation (2). The results show that in terms of the total GDP, the estimated coefficient $\rho$ of each dummy variable is not significant during the five years before the high-speed rail opened. This suggests that the GDP growth trends for the treatment group and the control group are not significantly different before the rail line opened. From the first year after the opening, $\rho$ has improved considerably with a higher significance level, indicating that there is a significant difference in the growth trends of total GDP between the treatment group and the control group.

In terms of per capita GDP, $\rho$ was not significant within the five years before and two years after the opening of the high-speed rail. This indicates that during this period, there was no significant difference in the growth trends of per capita GDP between the treatment and control groups. Three years after the opening, $\rho$ increased significantly, indicating that the per capita GDP growth trends of the two groups were significantly different at this period. It also suggests that the influence of high-speed rail on economic growth may have a two-year lag effect. As well, since the trend of economic growth of the two groups is comparable before the opening of high-speed rail, the parallel trend hypothesis is established. 


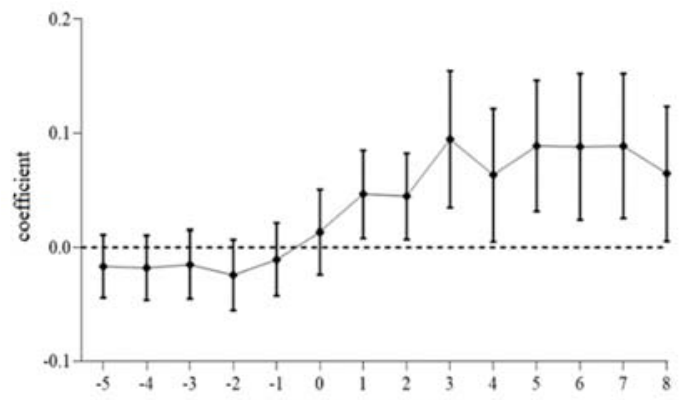

(a) Parallel trend test-lngdp

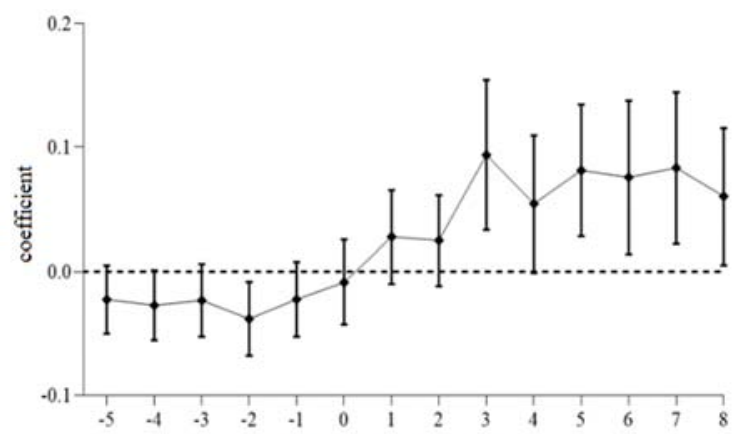

(b) Parallel trend test-lnpgdp

Figure 2. Parallel trend test.(a) Parallel trend test-lngdp; (b) Parallel trend test-lnpgdp.

\subsection{Robustness Test}

\subsubsection{Placebo Test}

Although we have controlled for several urban economic characteristics, urban fixed effects, and year fixed effects in the benchmark regression model, some other unobserved factors that may affect urban economic growth could have been overlooked. In other words, the economic growth of cities along the New Silk Road Economic Belt may have been influenced by other unobserved factors other than the high-speed rail opening. To test whether these unobserved factors affected the benchmark estimation results, we conducted a randomized placebo test. The placebo test was conducted as follows: we first randomized the year for high-speed rail opening and repeated this random process for 500 times. We then analyzed the distribution of the estimated coefficients of $h s r$ under randomization. If the mean value of the $h s r$ estimated coefficient is close to 0 , this would mean that the unobserved random factors do not have significant influence over the benchmark estimation result. If the value is close to the benchmark result, then the unobserved random factors may have significant impact on urban economic growth, which would mean the benchmark model has a major problem regarding missing variables.

The results of the placebo test are shown in Figure 3, where Figure 3a shows the kernel density distribution of 500 randomized estimates of the $h s r$ coefficient with lngdp as the explained variable, and Figure $3 \mathrm{~b}$ has $\ln p g d p$ as the explained variable. Compared with the $h s r$ coefficient in the benchmark model, the mean values of the $h s r$ coefficients in Figure 3 are much closer to $0(0.0004$ for lngdp and 0.0001 for $\ln p g d p)$. This means that the unobserved random factors did not have significant impact on the benchmark results and that the benchmark regression model is robust [44].

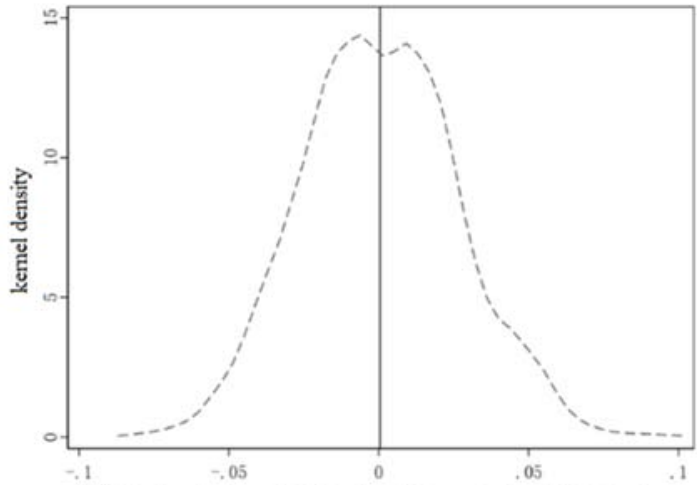

(a) Randomized coefficient estimate-Dependent variable: Ingdp

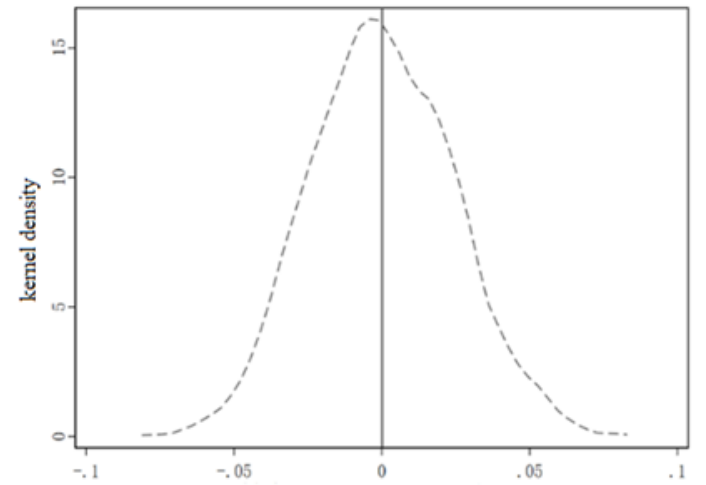

(b) Randomized coefficient estimate-Dependent variable: Inpgdp

Figure 3. Kernel density distribution with randomized coefficients.(a) Randomized coefficient estimate-lngdp; (b) Randomized coefficient estimate-lnpgdp. 


\subsubsection{Other Robustness Tests}

To ensure the robustness of the estimation results, we also conducted additional robustness tests. Aside from the randomized placebo test, the existing literature also suggests performing a counterfactual test by modifying the time of event in order to rule out the effect of political and/or random factors. Based on the recommendations of previous studies, we uniformly adjusted the date for the high-speed rail opening in each city by 2-3 years ahead of the actual schedule. If the estimated coefficient of the $h s r$ variable is still positive and statistically significant, this would indicate that the difference in economic growth more likely resulted from other factors and not the opening of the high-speed rail. If the estimation is not significant, this would then suggest that the opening of the high-speed rail produced the difference in economic growth.

Table 3 summarizes the results of the other robustness tests, where Columns 1 and 2 show the results when the high-speed rail was assumed to open two years in advance, and Columns 3 and 4 show the results when the opening was assumed to be three years early. The results show that the estimated coefficients of the modified $h s r$ variables are not significant, which indicates that the difference in economic growth is the result of the opening of the high-speed rail.

Table 3. Regression results of the benchmark model.

\begin{tabular}{ccccc}
\hline Variable & $\mathbf{( 1 )}$ & $\mathbf{( 2 )}$ & $\mathbf{( 3 )}$ & $\mathbf{( 4 )}$ \\
\cline { 2 - 5 } & $\mathbf{l n} g d p$ & $\mathbf{l n} g d p$ & $\ln p g d p$ & $\ln p g d p$ \\
\hline$h s r$ & $0.039^{*}(0.021)$ & $0.035^{* * *}(0.013)$ & $0.030(0.020)$ & $0.024^{*}(0.013)$ \\
$\ln p o p$ & & $0.146(0.140)$ & & $0.004(0.042)$ \\
$\ln k$ & $0.110^{* * *}(0.025)$ & & $0.103^{* * *}(0.024)$ \\
$\ln s$ & & $0.459^{* * *}(0.045)$ & & $0.414^{* * *}(0.042)$ \\
$\ln w a g e$ & & $0.122^{* *}(0.058)$ & & $0.125^{* *}(0.058)$ \\
inno & & $0.001(0.001)$ & & $0.000(0.001)$ \\
$\ln f d i$ & & $-0.007(0.004)$ & & $-0.003(0.004)$ \\
$\ln f i n a$ & & $-0.275^{* * *}(0.027)$ & & $-0.304^{* * *}(0.026)$ \\
Constant term & $15.308^{* * *}(0.006)$ & $14.306^{* * *}(0.858)$ & $9.867^{* * *}(0.005)$ & $8.108^{* * *}(0.641)$ \\
Urban fixation & Control & Control & Control & Control \\
Fixed time & Control & Control & Control & Control \\
$\mathrm{N}$ & 1157 & 1157 & 1157 & 1157 \\
AR & & 0.988 & 0.966 & 0.984 \\
\hline
\end{tabular}

Note: Within the brackets are robust standard errors. ${ }^{*}, * *$, and ${ }^{* * *}$ indicate significance levels of $10 \%, 5 \%$, and $1 \%$, respectively. AR2 is the adjusted goodness-of-fit.

In addition to the counterfactual test, we have also conducted other traditional robustness tests. The economic growth in provincial capital cities is usually more pronounced, which could have some effect on our estimation results. When the provincial capital cities were excluded (see Columns 5 and 6 of Table 4), the estimated results show that the coefficient of $h s r$ is still positive and significant.

There may also be some endogenous problems existing between high-speed rail opening and economic growth. Early high-speed rails were generally upgraded and renovated from existing railway trunk lines [19]. Many of the cities along these lines are already economically well-developed, and the estimation results of OLS may not be consistent and unbiased. To overcome this problem, we used the $h s r$ lagged variable as instrumental variable and performed the 2SLS estimation. The endogenous explanatory variable has a correlation with its lagged variable, but since the latter has already occurred, as a pre-determined variable, it has no correlation with the current disturbance term. Columns 7 and 8 from Table 4 show the 2SLS estimation results. The estimated coefficient of $h s r$ remains positive, and the F statistic is greater than 10 . This means that the weak instrumental variable problem is not present in this study. Also, the Sargan statistic is not significant, indicating that the instrumental variable is valid. Therefore, the estimated results are generally stable. 
Table 4. Results of the other robustness tests.

\begin{tabular}{|c|c|c|c|c|c|c|c|c|}
\hline & \multicolumn{2}{|c|}{$\begin{array}{c}\text { Opening Time } 2 \\
\text { Years Ahead }\end{array}$} & \multicolumn{2}{|c|}{$\begin{array}{c}\text { Opening Time } 3 \\
\text { Years Ahead }\end{array}$} & \multicolumn{2}{|c|}{$\begin{array}{l}\text { Without Provincial } \\
\text { Capital Cities }\end{array}$} & \multicolumn{2}{|c|}{ 2SLS } \\
\hline & (1) & (2) & (3) & (4) & (5) & (6) & (7) & (8) \\
\hline & $\ln g d p$ & $\ln p g d p$ & $\ln g d p$ & $\ln p g d p$ & $\ln g d p$ & $\ln p g d p$ & $\ln g d p$ & $\ln p g d p$ \\
\hline L2_hsr & $\begin{array}{c}0.010 \\
(0.012)\end{array}$ & $\begin{array}{l}-0.002 \\
(0.012)\end{array}$ & & & & & & \\
\hline L3_hsr & & & $\begin{array}{c}0.003 \\
(0.012)\end{array}$ & $\begin{array}{l}-0.008 \\
(0.012)\end{array}$ & & & & \\
\hline$h s r$ & & & & & $\begin{array}{l}0.035^{* *} \\
(0.015)\end{array}$ & $\begin{array}{l}0.023^{*} \\
(0.014)\end{array}$ & $\begin{array}{c}0.057^{* * *} \\
(0.018)\end{array}$ & $\begin{array}{c}0.051^{* * *} \\
(0.017)\end{array}$ \\
\hline F & & & & & & & 247.040 & 247.040 \\
\hline Sargan & & & & & & & 1.282 & 2.291 \\
\hline $\begin{array}{l}\text { Control } \\
\text { variable }\end{array}$ & Controlled & Controlled & Controlled & Controlled & Controlled & Controlled & Controlled & Controlled \\
\hline $\begin{array}{l}\text { Urban } \\
\text { fixed }\end{array}$ & Controlled & Controlled & Controlled & Controlled & Controlled & Controlled & Controlled & Controlled \\
\hline $\begin{array}{l}\text { Time } \\
\text { fixed }\end{array}$ & Controlled & Controlled & Controlled & Controlled & Controlled & Controlled & Controlled & Controlled \\
\hline $\mathrm{N}$ & 1157 & 1157 & 1157 & 1157 & 1053 & 1053 & 1157 & 1157 \\
\hline $\mathrm{AR}^{2}$ & 0.988 & 0.984 & 0.988 & 0.984 & 0.985 & 0.983 & 0.513 & 0.516 \\
\hline
\end{tabular}

Note: Within the brackets are robust standard errors. ${ }^{*}, * *$, and ${ }^{* * *}$ indicate significance levels of $10 \%, 5 \%$, and $1 \%$, respectively.

\section{Further Heterogeneity Analysis}

The benchmark model and robustness tests have confirmed that the opening of high-speed rail has significantly promoted economic growth in cities along the New Silk Road Economic Belt. However, as noted in the theoretical analysis (see Section 3), the effect of high-speed rail opening on economic growth can also be influenced by the size of the city, the degree of marketization, and the efficiency of the government. Therefore, in this section, we further analyze the above heterogeneities to derive more detailed conclusions.

\subsection{Urban Scale Heterogeneity}

To test Hypothesis 2, we divided our sample cities into small and medium-sized cities (with fewer than one million residents) and large cities (with more than one million residents). This classification is in accordance with the "Notice on Adjusting the Standards for the Division of Urban Scale" issued by the State Council of China in 2014 (The State Council issued the notice on adjusting the standard of urban scale division (2014), which clarifies that the new standard of urban scale division takes the permanent population of urban area as the statistical standard and divides cities into five categories and seven grades. Cities with a permanent population of less than 500000 in urban area are small cities: among which, cities with a permanent population of more than 200000 but less than 500000 are Type I small cities; and, cities with a permanent population of less than 200000 are Type II small cities. Cities with a resident population of more than 500000 but less than 1 million are medium-sized cities. Cities with more than 1 million but less than 5 million are big cities: among which, cities with more than 3 million but less than 5 million are type I; and, cities with more than 1 million but less than 3 million are type II. Cities with more than 5 million but less than 10 million permanent residents in urban areas are megacities. Cities with more than 10 million permanent residents in urban areas are megacities [45].), which uses urban resident population data when categorizing cities. Since this data is not listed in the statistical yearbook, we used the population of municipal districts as replacement. The sample estimation results are shown in Table 4.

Under different city scales, the economic growth effects of high-speed rail opening are all positive and significant; however, the magnitudes of the growth effect do vary. The hsr coefficients for small and medium-sized cities are smaller than in the large cities, which indicates that the economic growth effect of high-speed rail opening demonstrates some degree of urban-scale heterogeneity. The opening of high-speed rail in big cities attracts resources from the surrounding small and medium-sized 
cities and other city elements along the route. This generates a more substantial siphoning effect, which makes the impact on economic growth much stronger. For small and medium-sized cities, due to the detachment of resources, the economic growth effect brought by the high-speed rail was found to be comparatively weaker.

From the results of the control variables in Table 5, capital investment has a significant impact on the economic growth of different scale cities, showing a positive relationship. Labor input has a significant impact on the overall economic growth of big cities, showing a positive relationship, which is consistent with expectations. The industrial structure has a positive relationship with the economic growth of different scale cities, with a high level of significance, consistent with the expected symbols. The innovation level has a significant impact on the economic growth of big cities, showing a positive relationship. The impact of financial level has a significant negative correlation on urban economic growth. The reason may be that the cities along the Silk Road Economic Belt are located in the western region where the financial development level is relatively backward. The uncoordinated levels of financial development and technological progress may inhibit the economic growth of the region. Foreign direct investment has a significant positive correlation with the economic growth of big cities but has no significant impact on the economic growth of small and medium-sized cities. The reason may be that foreign direct investment is mainly concentrated in big cities, which plays a substantial role in promoting economic growth. The impact of wage level on the economic growth of big cities is not significant, and the impact on the economic growth of small and medium-sized cities is relatively significant. The reason may be that most of the big cities along the Western Silk Road Economic Belt are resource-based cities. As well, compared with small and medium-sized cities, the investment scale plays a greater role in promoting national economic growth, and the impact of wage level is relatively small.

Table 5. Urban size heterogeneity.

\begin{tabular}{ccccc}
\hline \multirow{2}{*}{ Variable } & \multicolumn{2}{c}{ Medium and Small Cities } & \multicolumn{2}{c}{ Big Cities } \\
\cline { 2 - 5 } & $\mathbf{( 1 )}$ & $\mathbf{( 2 )}$ & $\mathbf{( 3 )}$ & $\mathbf{( 4 )}$ \\
& $\mathbf{l n} g d p$ & $\mathbf{l n} p g d p$ & $\mathbf{l n g d p}$ & $\mathbf{l n} p g d p$ \\
\hline \multirow{2}{*}{$h s r$} & $0.041^{* *}$ & $0.038^{* *}$ & $0.054^{* * *}$ & $0.058^{* * *}$ \\
& $(0.017)$ & $(0.016)$ & $(0.020)$ & $(0.019)$ \\
$\ln p o p$ & 0.127 & 0.009 & $1.213^{* * *}$ & 0.361 \\
& $(0.126)$ & $(0.041)$ & $(0.203)$ & $(0.225)$ \\
$\ln k$ & $0.110^{* * *}$ & $0.099^{* * *}$ & $0.102^{* * *}$ & $0.121^{* * *}$ \\
& $(0.030)$ & $(0.028)$ & $(0.039)$ & $(0.041)$ \\
$\ln s$ & $0.484^{* * *}$ & $0.439^{* * *}$ & $0.325^{* * *}$ & $0.303^{* * *}$ \\
& $(0.048)$ & $(0.044)$ & $(0.105)$ & $(0.100)$ \\
$\ln w a g e$ & $0.115^{* *}$ & $0.116^{* *}$ & 0.105 & 0.100 \\
& $(0.058)$ & $(0.057)$ & $(0.075)$ & $(0.073)$ \\
inno & -0.000 & -0.010 & $0.001^{* * *}$ & $0.001^{* * *}$ \\
& $(0.010)$ & $(0.008)$ & $(0.000)$ & $(0.000)$ \\
$\ln f d i$ & $-0.011^{*}$ & -0.006 & $0.016^{* *}$ & $0.015^{* * *}$ \\
& $(0.005)$ & $(0.005)$ & $(0.007)$ & $(0.007)$ \\
$\ln f i n a$ & $-0.222^{* * *}$ & $-0.253^{* * *}$ & $-0.439^{* * *}$ & $-0.399^{* * *}$ \\
& $(0.031)$ & $(0.029)$ & $(0.055)$ & $(0.057)$ \\
Constant term & $14.129^{* * *}$ & $8.238^{* * *}$ & $18.807^{* * *}$ & $9.559^{* * * *}$ \\
Urban fixed & $(0.836)$ & $(0.634)$ & $(1.263)$ & $(1.331)$ \\
Time fixed & Controlled & Controlled & Controlled & Controlled \\
$\mathrm{N}$ & Controlled & Controlled & Controlled & Controlled \\
AR & 712 & 712 & 260 & 260 \\
& 0.980 & 0.981 & 0.995 & 0.993 \\
\hline
\end{tabular}

Note: Within the brackets are robust standard errors. ${ }^{*}, * *$, and ${ }^{* * *}$ indicate significance levels of $10 \%, 5 \%$, and $1 \%$, respectively.

\subsection{Marketization Level and Government Efficiency Heterogeneity}

To test Hypotheses 3 and 4, we differentiated the sample cities in terms of marketization level and government efficiency. Marketization is a transition from a planned economy towards a market 
economy. It is not a simple change of several rules and regulations, but rather a series of economic, social and legal system changes [46], or a series of large-scale institutional changes. For the marketization level, we adopted the indicator of "marketization degree" for each province, as compiled by Fan et al. (2010) (We refer to Fan et al. (2011) regarding the definition and measurement of marketization. A marketization index can be calculated based on five subdivided "aspect indexes", namely: (1) the relationship between government and market, (2) the development of non-state-owned economy, (3) the development of product market, (4) the development of factor market, and (5) the development of market intermediary organizations and legal system environment. These categories can be further subdivided, constituting an index system with 23 base-level indexes [47].) The 12 provinces and regions were divided into two groups of high and low marketization levels using the initial indicators in 2004. For government efficiency, we used the 2016 China Local Government Efficiency Research Report. Similarly, the samples were divided into two groups of high and low efficiency using government efficiency indicators in 2016.

The estimated results in Table 6 show that in areas with high marketization levels and high government efficiency, the impact of high-speed rail opening on economic growth is more significant. In areas with low marketization levels and low government efficiency, the impact is not as distinct. These results validate Hypotheses 3 and 4. In areas with a higher degree of marketization, the opening of high-speed rail further optimizes the spatial allocation of capital elements, thereby promoting economic growth. Also, in areas with high government efficiency, administrative costs for enterprises would generally be lower. Thus, high-speed rail provides a higher chance of attracting more resource elements that would further promote local economic growth.

Table 6. Marketization level heterogeneity and government efficiency heterogeneity.

\begin{tabular}{|c|c|c|c|c|c|c|c|c|}
\hline & \multicolumn{4}{|c|}{ Marketization Level } & \multicolumn{4}{|c|}{ Government Efficiency } \\
\hline & \multicolumn{2}{|c|}{ Low } & \multicolumn{2}{|c|}{ High } & \multicolumn{2}{|c|}{ Low } & \multicolumn{2}{|c|}{ High } \\
\hline & (1) & (2) & (3) & (4) & (5) & (6) & (7) & (8) \\
\hline & $\ln g d p$ & $\ln p g d p$ & $\ln g d p$ & $\ln p g d p$ & $\ln g d p$ & $\ln p g d p$ & $\ln g d p$ & $\ln p g d p$ \\
\hline$h s r$ & $\begin{array}{c}0.032 \\
(0.035)\end{array}$ & $\begin{array}{c}0.048 \\
(0.042)\end{array}$ & $\begin{array}{c}0.039^{* * *} \\
(0.014)\end{array}$ & $\begin{array}{l}0.024^{*} \\
(0.014)\end{array}$ & $\begin{array}{l}-0.003 \\
(0.019)\end{array}$ & $\begin{array}{l}-0.010 \\
(0.019)\end{array}$ & $\begin{array}{c}0.063^{* * *} \\
(0.017)\end{array}$ & $\begin{array}{c}0.051^{* * *} \\
(0.016)\end{array}$ \\
\hline $\ln p o p$ & $\begin{array}{c}0.262 \\
(0.162)\end{array}$ & $\begin{array}{c}-0.399^{* * *} \\
(0.189)\end{array}$ & $\begin{array}{c}0.100 \\
(0.115)\end{array}$ & $\begin{array}{c}0.011 \\
(0.049)\end{array}$ & $\begin{array}{c}1.073^{* * *} \\
(0.180)\end{array}$ & $\begin{array}{c}0.417^{* * *} \\
(0.152)\end{array}$ & $\begin{array}{c}0.073 \\
(0.075)\end{array}$ & $\begin{array}{l}-0.018 \\
(0.021)\end{array}$ \\
\hline $\ln k$ & $\begin{array}{c}0.136^{* * *} \\
(0.034)\end{array}$ & $\begin{array}{c}0.131^{* * *} \\
(0.033)\end{array}$ & $\begin{array}{c}0.101^{* * *} \\
(0.030)\end{array}$ & $\begin{array}{c}0.090^{* * *} \\
(0.027)\end{array}$ & $\begin{array}{c}0.148^{* * *} \\
(0.038)\end{array}$ & $\begin{array}{c}0.138^{* * *} \\
(0.037)\end{array}$ & $\begin{array}{l}0.059^{* *} \\
(0.029)\end{array}$ & $\begin{array}{l}0.063^{* *} \\
(0.027)\end{array}$ \\
\hline $\ln s$ & $\begin{array}{c}0.229^{* * * *} \\
(0.076)\end{array}$ & $\begin{array}{c}0.282^{* * *} \\
(0.091)\end{array}$ & $\begin{array}{c}0.482^{* * * *} \\
(0.047)\end{array}$ & $\begin{array}{c}0.430^{* * * *} \\
(0.045)\end{array}$ & $\begin{array}{c}0.441^{* * *} \\
(0.057)\end{array}$ & $\begin{array}{c}0.423^{* * *} \\
(0.056)\end{array}$ & $\begin{array}{c}0.351^{* * *} \\
(0.070)\end{array}$ & $\begin{array}{c}0.294^{* * * *} \\
(0.062)\end{array}$ \\
\hline $\ln w a g e$ & $\begin{array}{c}0.163 \\
(0.108)\end{array}$ & $\begin{array}{l}0.216^{* *} \\
(0.105)\end{array}$ & $\begin{array}{l}0.113^{*} \\
(0.060)\end{array}$ & $\begin{array}{l}0.106^{*} \\
(0.057)\end{array}$ & $\begin{array}{l}0.101^{*} \\
(0.057)\end{array}$ & $\begin{array}{l}0.103^{*} \\
(0.057)\end{array}$ & $\begin{array}{c}0.181^{* * *} \\
(0.064)\end{array}$ & $\begin{array}{c}0.191^{* * *} \\
(0.059)\end{array}$ \\
\hline inno & $\begin{array}{l}0.007^{*} \\
(0.004)\end{array}$ & $\begin{array}{c}0.002 \\
(0.005)\end{array}$ & $\begin{array}{c}0.001 \\
(0.001)\end{array}$ & $\begin{array}{c}0.000 \\
(0.001)\end{array}$ & $\begin{array}{l}-0.001 \\
(0.004)\end{array}$ & $\begin{array}{l}-0.002 \\
(0.005)\end{array}$ & $\begin{array}{c}0.000 \\
(0.001)\end{array}$ & $\begin{array}{c}0.000 \\
(0.001)\end{array}$ \\
\hline $\ln f d i$ & $\begin{array}{l}-0.007 \\
(0.005)\end{array}$ & $\begin{array}{c}-0.009^{*} \\
(0.005)\end{array}$ & $\begin{array}{l}-0.007 \\
(0.006)\end{array}$ & $\begin{array}{l}-0.001 \\
(0.005)\end{array}$ & $\begin{array}{l}-0.006 \\
(0.005)\end{array}$ & $\begin{array}{l}-0.004 \\
(0.005)\end{array}$ & $\begin{array}{c}0.000 \\
(0.006)\end{array}$ & $\begin{array}{c}0.004 \\
(0.005)\end{array}$ \\
\hline $\ln f i n a$ & $\begin{array}{c}-0.348^{* * *} \\
(0.027)\end{array}$ & $\begin{array}{c}-0.340^{* * * *} \\
(0.031)\end{array}$ & $\begin{array}{c}-0.274^{* * *} \\
(0.032)\end{array}$ & $\begin{array}{c}-0.310^{* * *} \\
(0.030)\end{array}$ & $\begin{array}{c}-0.259^{* * * *} \\
(0.042)\end{array}$ & $\begin{array}{c}-0.265^{* * *} \\
(0.042)\end{array}$ & $\begin{array}{c}-0.313^{* * * *} \\
(0.029)\end{array}$ & $\begin{array}{c}-0.350^{* * *} \\
(0.028)\end{array}$ \\
\hline Constant term & $\begin{array}{c}13.712^{* * *} \\
(0.844)\end{array}$ & $\begin{array}{c}4.880^{* * * *} \\
(0.816)\end{array}$ & $\begin{array}{c}14.352^{* * * *} \\
(0.824)\end{array}$ & $\begin{array}{c}8.467^{* * * *} \\
(0.655)\end{array}$ & $\begin{array}{c}18.278^{* * * *} \\
(0.952)\end{array}$ & $\begin{array}{c}9.876^{* * * *} \\
(0.838)\end{array}$ & $\begin{array}{c}13.808^{* * *} \\
(0.734)\end{array}$ & $\begin{array}{c}7.621^{* * *} \\
(0.642)\end{array}$ \\
\hline Urban fixed & Controlled & Controlled & Controlled & Controlled & Controlled & Controlled & Controlled & Controlled \\
\hline $\begin{array}{c}\text { Time fixed } \\
\mathbf{N}\end{array}$ & $\begin{array}{l}\text { Controlled } \\
166\end{array}$ & $\begin{array}{c}\text { Controlled } \\
166\end{array}$ & $\begin{array}{l}\text { Controlled } \\
806\end{array}$ & $\begin{array}{l}\text { Controlled } \\
806\end{array}$ & $\begin{array}{c}\text { Controlled } \\
474\end{array}$ & $\begin{array}{c}\text { Controlled } \\
474\end{array}$ & $\begin{array}{c}\text { Controlled } \\
498\end{array}$ & $\begin{array}{c}\text { Controlled } \\
498\end{array}$ \\
\hline $\mathrm{AR}^{2}$ & 0.995 & 0.993 & 0.986 & 0.981 & 0.982 & 0.979 & 0.993 & 0.989 \\
\hline
\end{tabular}

Note: Within the brackets are robust standard errors. ${ }^{*}, * *$, and ${ }^{* * *}$ indicate significance levels of $10 \%, 5 \%$, and $1 \%$, respectively.

\section{Conclusions and Policy Implications}

The priority task in promoting the development of trades along the "Belt and Road" is to establish a smooth regional transportation network. In his study, we used a quasi-natural experiment to study the impact of high-speed rail opening on the economic growth of cities along the New Silk Road Economic Belt. Our results show that following the opening of high-speed rail, significant increases in economic growth were observed both in terms of total GDP and per capita GDP. 
Furthermore, the impact of high-speed rail opening on economic growth showed distinct heterogeneity. Large cities, having stronger siphoning effect, exhibited stronger economic growth as a result of high-speed rail opening. Also, cities with higher marketization levels and higher government efficiency were shown to have stronger economic growth effect, resulting from higher efficiency in resource allocation.

The conclusions of this research lead to a number of important policy implications and recommendations. First, in order to accelerate the process of regional integration, greater investments have to be made with regard to the construction and improvement of the transportation infrastructure along the "Belt" region. The results from this study show that high-speed rail can significantly affect city and regional economies and highlight the crucial role of transportation infrastructure in promoting economic growth.

Second, large-scale urban centers can be used to more effectively attract essential resources and magnify the effect of high-speed rail in promoting economic growth. The heterogeneity analyses show that the economic effect of high-speed rail in big cities is higher, highlighting their stronger ability for economic agglomeration and growth potential. At the same time, decision-makers have to be cautious not to overlook other areas for growth. Excessive expansion may develop into resource mismatch, which would result in large scale urban areas with no agglomeration capacity.

Third, policymakers should be more cognizant of the roles and the relationship between the government and the market. The heterogeneity analyses show that the positive impact of high-speed rail is more robust in cities with higher degrees of marketization and higher government efficiency. This suggests that while construction of transportation infrastructure can provide some agglomeration advantage, effective market mechanisms and sufficient government support have to be in place to achieve efficient allocation of factor resources and guide the development of industries. In areas where market mechanisms do work, the government should actively promote marketization and support the market to achieve its potential in resource allocation. In areas where market mechanisms fail, the government should proactively improve administrative efficiency and use its "visible hands" to make up for market failures.

Our study does have some limitations, most of which hinge on the research level. We mainly examined the impact of high-speed rail on the economic growth of cities along the Silk Road Economic Belt from a relatively macro level, while the internal channel or the micro basis of these effects have not been covered. For example, whether the opening of high-speed rail has changed the production activities of enterprises in cities along the route and the pattern of population flow in these cities are research topics for further exploration. With the enrichment of micro-level data and the expansion of sample size, these could be considered as directions for future research of this paper.

Author Contributions: Data curation, W.Z. and Y.S.; Provision of study materials, F.L. and J.X.; methodology, J.X. and Y.S.; supervision, F.L. and Y.W.; writing—original draft, F.L.; writing-review and editing, W.Z., Y.S. and F.L.; All authors have read and agreed to the published version of the manuscript.

Funding: The work was supported by the Natural Science Foundation of Xinjiang Uygur Autonomous Region of China(Grant No.2017D01B07), China Postdoctoral fund (Grant No.2018M633654XB) and 2016 talent training program for 100 young doctors in Xinjiang Uygur Autonomous Region of China.

Acknowledgments: The authors contributed equally to the paper and author names are in alphabetical order. The authors thank the editor, and the anonymous reviewers for their valuable suggestions that have significantly improved this study.Special thanks to the professional English editing service from EditX, and Thanks for Huang Xianke's support and help.

Conflicts of Interest: The authors declare no competing interest. All authors state that no financial and personal relationships with other people or organizations that could inappropriately influence (bias) their work.

\section{References}

1. Donaldson, D. Railroads of the Raj: Estimating the Impact of Transportation Infrastructure. Am. Econ. Rev. 2010, 4-5, 899-934. 
2. Xueliang, Z. Does China's Transportation Infrastructure Promote Regional Economic Growth? Concurrently on the Spatial Spillover Effect of Transportation Infrastructure. Chin. Soc. Sci. 2012, 3, 60-77.

3. Rodan, P.R. Problems of Industrialization of Eastern and South-Eastern Europe. Econ. J. 1943, 53, $202-211$. [CrossRef]

4. Nurkse, R. The capacity of the market and the lure of investment. In Problems of Capital Formation in Underdeveloped Countries; Zhai, J., Ed.; Commercial Press: Beijing, China, 1966; pp. 6-26.

5. Rostow, W. Six stages of growth. In The Stages of Economic Growth: A Non-Communist Manifesto; Cambridge University Press: Cambridge, UK, 1960; pp. 6-10.

6. Kim, K.S. High-Speed Rail Developments and Spatial Restructuring: A Case Study of the Capital Region in South Korea. Cities 2000, 4, 251-262. [CrossRef]

7. Albalate, D. High Speed Rail and Tourism: Empirical Evidence from Spain's Provinces and Cities. Transp. Res. 2016, 1, 174-185.

8. Jianfeng, W.; Zhigang, L. Empirical Analysis of the Impact of Shanghai-Hangzhou High-speed rail on Regional Economic Development along the Line. Explor. Econ. Issues 2014, 9, 74-77.

9. Xinguang, L.; Anmin, H.; Yongqi, Z. Evaluation of the Impact of High-speed Rail on Regional Economic Development-An Empirical Analysis of Fujian Province Based on DID Model. Mod. Urban Res. 2017, 4, 125-132.

10. Givoni, M. Development and impact of the modern high-speed train:a review. Transp. Rev. 2006, 5, 593-611. [CrossRef]

11. Yu, F.; Lin, F.; Tang, Y.; Zhong, C. High-speed railway to success? The effects of high-speed rail connection on regional economic development in China. J. Reg. Sci. 2019, 4, 723-742. [CrossRef]

12. Shi, J.; Zhou, N. How Cites Influenced by High Speed Rail Development: A Case Study in China. J. Transp. Technol. 2013,3,7-16. [CrossRef]

13. Chen, L.; Long, C.; Wang, D.; Yang, J. Phytoremediation of cadmium (Cd) and uranium (U) contaminated soils by Brassica juncea L. enhanced with exogenous application of plant growth regulators. Chemosphere 2020, 242, 125112. [CrossRef] [PubMed]

14. Chenglin, Q.; Zhaohui, Z. Development of High-speed rail and Economic Agglomeration of Cities along Railways. Explor. Econ. Issues 2014, 5, 163-169.

15. Shao, S.; Tian, Z.; Yang, L. High speed rail and urban service industry agglomeration: Evidence from China's Yangtze River Delta Region. J. Transp. Geogr. 2017, 64, 174-183. [CrossRef]

16. Fucai, L.; Zhan Xianzhi, Z. Research on the Impact of High-speed rail on Industrial Agglomeration in Cities along the Line-An Empirical Analysis Based on Panel Data of Central Cities. Contemp. Financ. Econ. 2017, 11, 88-99.

17. Chunfang, H.; Qing, H. Does the high-speed rail line have a "shadow of Agglomeration" on urban economic activities? -Evidence from night lights in cities around Beijing Shanghai high speed railway. Shanghai Econ. Res. 2019, 11, 46-58.

18. Hall, P. Magic Carpets and Seamless Webs: Opportunities and Constraints for High-speed Trains in Europe. Built Environ. 2009, 1, 59-69. [CrossRef]

19. Ke Zhong, Z.; Dongjie, T. Economic Distribution Effect of Transportation Infrastructure. Evidence from the Opening of High-speed Rail. Economics 2016, 6, 62-73.

20. Chen, Z.; Haynes, K.E. Impact of high-speed rail on regional economic disparity in China. J. Transp. Geogr. 2017, 8, 80-91. [CrossRef]

21. Hongchang, L.; Linda, T.; Hu, S.X. Influence of China's High Speed Railway on Economic Agglomeration and Equalization of Cities along the Line. J. Ind. Econ. Quant. 2016, 11, 127-143.

22. Xinguang, L.; Anmin, H. Research on the Impact of High-speed Rail on the Spillover Effect of County Economic Growth-Taking Fujian Province as an Example. Geogr. Sci. 2018, 2, 233-241.

23. Song, W.J.; Zhu, Q.; Zhu, Y.M.; Kong, C.C.; Shi, Y.J.; Gu, Y.T. The impact of high-speed rail on the development of different scale cities. Econ. Geogr. 2015, 35, 57-63.

24. Liu, L.; Zhang, M. High-speed rail impacts on travel times, accessibility, and economic productivity: A benchmarking analysis in city-cluster regions of China. J. Transp. Geogr. 2018, 73, 25-40. [CrossRef]

25. Jie, X.; Ming, Z.; Xiaoling, Z.; Di, Z.; Yina, Z. How does City-cluster high-speed rail facilitate regional integration? Evidence from the Shanghai-Nanjing corridor. Cities 2019, 85, 83-97.

26. Xinze, L.; Xiaole, L.; Lingling, Z. Can high-speed rail improve enterprise resource allocation? Microscopic evidence from Chinese industrial enterprise database and high-speed rail geographic data. Econ. Rev. 2017, 6, 3-21. 
27. Xingqiang, D.; Miaowei, P. Will the opening of the high-speed rail promote the flow of senior talents in enterprises? Econ. Manag. 2017, 12, 89-107.

28. Jianhua, T.; Hongyan, D.; Zhidong, T. High-speed rail opening and enterprise innovation-based on the quasi-natural experiment of high-speed rail opening. J. Shanxi Univ. Financ. Econ. 2019, 3, 60-70.

29. Yu, L.; Hailong, Z.; Xinde, Z.; Tao, L. Venture Capital under Time and Space Compression—Regional Change of High-speed Rail and Risk Investment. Econ. Res. 2017, 4, 195-208.

30. Wen, W.; Yuting, H.; Jianbo, S. Does the construction of transportation infrastructure improve the efficiency of enterprise investment? Based on the quasi-natural experiment of China's high-speed rail opening. J. Zhongnan Univ. Econ. Law 2019, 2, 42-52.

31. Kainan, H.; Guangzhao, S. How does the high-speed rail opening affect the total factor productivity of enterprises? Based on the research of listed companies in China's manufacturing industry. J. China Univ. Geosci. 2019, 1, 144-157.

32. Cantos, P.; Gumbau-Albert, M.; Maudos, J. Transport Infrastructures, Spillover Effects and Regional Growth: Evidence of the Spanish Case. Transp. Rev. 2005, 1, 25-50. [CrossRef]

33. Wei, W.; Jingjuan, J.; Fengjun, J. The influence of high-speed rail on the spatial interaction intensity of Chinese cities. Acta Geogr. Sin. 2014, 2, 1833-1846.

34. Xiaowen, Z. The Promotion of High-speed rail to the Coordinated Development of Regional Economy. Railw. Econ. Econ. Res. 2010, 6, 19-22.

35. Chenglin, Q.; Qingqing, Y. The impact of high-speed rail on the spatial pattern change of producer service industry. Econ. Geogr. 2017, 2, 90-97.

36. Puga, D. European Regional Policies in Light of Recent Location Theories. Cepr Discuss. Pap. 2002, 4, 113-150. [CrossRef]

37. Liwen, L.; Ming, Z. The Impact of High Speed Railway on China's Urban Accessibility and Regional Economy. Int. Urban Plan. 2017, 4, 76-81.

38. Yifu, L. New Structural Economics, Viability and New Theoretical Insights. J. Wuhan Univ. 2017, 6, 5-15.

39. Zhihua, R.; Wenhua, L.; Sanggyun, N.; Xianhua, T.; Tianqiao, X. Regional Marketization, OFDI, and Sustainable Employment: Empirical Analysis in China. Sustainability. 2019, 15, 4101.

40. Jie, Z. Measurement, Change Mechanism and Government Intervention Effect of China's Manufacturing Factor Efficient Efficiency. J. Stat. Res. 2016, 3, 72-79.

41. Yuanchao, B.; Lihua, W.; Junhong, B. High-speed rail opening, factor flow and regional economic disparity. Financ. Trade 2018, 6, 147-161.

42. Jun, Z.; Guiying, W.; Jipeng, Z. Estimation of China's inter provincial material capital stock: 1952-2000. Econ. Res. 2004, 10, 35-44.

43. Ashenfelter O, C. Estimating the Effect of Training Programs on Earnings. Rev. Econ. Stat. 1978, 1, 47-57. [CrossRef]

44. Huajun, S.; Erming, C. Double difference method of policy effect evaluation. Stat. Decis. 2017, 17, 80-83.

45. State Council 2014: Notice on Adjusting the Standard of City Scale Division. Available online: http: //www.gov.cn/zhengce/content/2014-11/20/content_.htm (accessed on 9 November 2019).

46. Gang, F.; Xiaolu, W.; Guangrong, M. Contribution of China's marketization process to economic growth. Econ. Res. 2011, 9, 4-16.

47. Gang, F.; Xiaolu, W.; Liwen, W.; Hengpeng, Z. Report on the relative process of marketization in various regions of China. Econ. Res. 2003, 3, 9-18.

(C) 2020 by the authors. Licensee MDPI, Basel, Switzerland. This article is an open access article distributed under the terms and conditions of the Creative Commons Attribution (CC BY) license (http://creativecommons.org/licenses/by/4.0/). 